\title{
$\mathrm{B}_{2} \mathrm{O}_{3}-\mathrm{Bi}_{2} \mathrm{O}_{3}-\mathrm{ZnO}$ 계 유리를 이용한 백색 LED용 색변환 렌즈의 광 특성
}

\author{
채유진 ${ }^{1}$, 이미재 ${ }^{1, a}$, 김진호 ${ }^{1}$, 황종희 ${ }^{1}$, 임태영 ${ }^{1}$, 정희석 $^{2}$, 이영식 ${ }^{3}$, 김득중 ${ }^{4}$ \\ 1 한국세라믹기술원 광 - 디스플레이소재팀 \\ 2 한국조명연구원 \\ ${ }^{3}$ (주)솔레즈 \\ ${ }^{4}$ 성균관대학교 신소재공학과
}

\section{Optical Properties of Color Conversion Lens for White LED Using $\mathrm{B}_{2} \mathrm{O}_{3}-\mathrm{Bi}_{2} \mathrm{O}_{3}-\mathrm{ZnO}$ Glass}

\author{
Yoo-Jin Chae ${ }^{1}$, Mi-Jai Lee ${ }^{1, a}$, Jin-Ho Kim ${ }^{1}$, Jong-Hee Hwang ${ }^{1}$, \\ Tae-Young Lim ${ }^{1}$, Hee-Suk Jeong ${ }^{2}$, Young-sik Lee ${ }^{3}$, and Deuk-Jung Kim ${ }^{4}$ \\ ${ }^{1}$ Korea Institute of Ceramics Engineering and Technology, Seoul 153-801, Korea \\ ${ }^{2}$ Korea Institute of Lighting Technology, Bucheon 420-130, Korea \\ ${ }^{3}$ Solleds Co. Ltd., Hwaseong 445-170, Korea \\ ${ }^{4}$ School of Advanced Materials Science \& Engineering, Sungkyunkwan University, Suwon 440-760, Korea
}

(Received July 18, 2013; Revised July 23, 2013; Accepted July 24, 2013)

\begin{abstract}
Recently, remote phosphor is reported for white LED enhancing of phosphor efficiency compared with conventional phosphor-based W-LED. In this study, Remote phosphor was produced by screen printing coating on glass substrate with phosphor contents rated paste and heat treatment. The paste consists of phosphor, lowest softening glass frit and organic binders. Remote phosphor can be well controlled by varying the phosphor content rated paste. After mounting remote phosphor on top of blue LED chip, CCT, CRI, and luminance efficiency were measured. The measurement results showed that CCT, CRI, and luminance efficiency were $6,645,68$, and $1,161 \mathrm{~m} / \mathrm{W}$ in phosphor $80 \mathrm{wt} . \%$ remote phosphor sintered at $600^{\circ} \mathrm{C}$.
\end{abstract}

Keywords: Remote phosphor, White LED package, Phosphor coatings, Glass

\section{1. 서 론}

LED는 효율이 높을 뿐만 아니라 무수은, 긴 수명

a. Corresponding author; im1004@kicet.re.kr

Copyright (C2013 KIEEME. All rights reserved.

This is an Open-Access article distributed under the terms of the Creative Commons Attribution Non-Commercial License (http://creativecommons.org/licenses/by-nc/3.0) which permits unrestricted non-commercial use, distribution, and reproduction in any medium, provided the original work is properly cited.
의 장점을 가지고 있어 기존의 조명을 대체하는 조명 으로 많은 연구가 진행되고 있다. 차세대 조명용 후 보광원인 백색 $\mathrm{LED}$ 를 제조하는 방법 중에서 높은 연 색성으로 인해 가장 많이 적용하는 방법은 청색 $\mathrm{LED}$ 와 황색 형광체를 함께 패키지화하여 백색 발광시키 는 방법이다. 단일 형광체를 사용하기 때문에 제조가 용이하고 황색 형광체의 광 변환 효율이 매우 높기 때문에 광 손실이 적다는 장점이 있다. 조명용으로 
사용하기 위한 백색 $\mathrm{LED}$ 패키지에서 신뢰성은 매우 중요한 요소로 실제 고온에 의한 LED 칩의 성능 저 하보다 패키지 제조에 사용된 봉지재와 형광체의 열 화현상으로 신뢰성 저하의 주요인으로 작용하고 있다 [1-3]

따라서 본 연구에서는 신뢰성 문제가 되는 실리콘 또는 에폭시 소재 대신 저 연화점 유리를 사용하여 remote-phosphor LED용 색 변환 렌즈를 제작하였다. 사 용된 유리는 $500^{\circ} \mathrm{C}$ 정도의 연화점을 갖는 $\mathrm{Bi}_{2} \mathrm{O}_{3}-\mathrm{B}_{2} \mathrm{O}_{3}-\mathrm{ZnO}$ 계 유리를 사용하였으며, 제조공정이 간단하고, 원하 는 모양 및 크기로 제조가 쉬운 스크린 프린팅법을 이용하여 제조하였다. 제조한 색변환 렌즈는 황색 형 광체 함량 및 열처리 조건에 따른 광 특성을 평가하 였다 [4-7].

\section{2. 실험 방법}

\section{1 유리 프릿 제조}

본 연구에서는 저 융점 유리의 형성을 위해 유리 수식제인 $\mathrm{Bi}_{2} \mathrm{O}_{3}, \mathrm{ZnO}$ 를 사용하였고, 유리 형성제로 $\mathrm{B}_{2} \mathrm{O}_{3}$ 를 선정하였으며, 이 조성계의 상평형도를 그림 1 에 나타내었다. 이 계에서 유리 형성되는 범위를 점 선으로 표시하였고, 유리형성 범위 안의 조성인 20 $\mathrm{mol} \% \mathrm{Bi}_{2} \mathrm{O}_{3}, 40 \mathrm{~mol} \% \mathrm{~B}_{2} \mathrm{O}_{3}, 40 \mathrm{~mol} \% \mathrm{ZnO}$ 를 선정하 여 실험을 진행하였다. 실험한 원료는 $\mathrm{Bi}_{2} \mathrm{O}_{3} \quad(99.0 \%$, DAEJUNG CHEMICAL \& METALS Co., Ltd.), $\mathrm{B}_{2} \mathrm{O}_{3}$ (99.0\%, SIGMA-ALDRICH, Inc., Germany), $\mathrm{ZnO}$ (99\%, Junsei Chemical Co., Ltd., Japan)를 사용 하였다. 조성에 따라 원료를 배치로 조합한 후 3시간 동안 건식 혼합하였다. 혼합한 원료를 $40 \Phi$ 직경 몰 드에 성형하였다. $1,000^{\circ} \mathrm{C}$ 에서 예열된 알루미나 도가 니에 원료를 넣어 20 분 간 용융하였다. 용융물을 Ribbon cullet 제조기에 부어 얇은 유리 벌크 상태로 제조하였다. 제조된 유리는 $1.2 \mathrm{~L}$ 알루미나 포트에 10 $\Phi$ 직경 알루미나 볼을 넣어 밀링머신으로 3 시간 동 안 $300 \mathrm{rpm}$ 으로 분쇄하여 글라스 프릿으로 제조하였 다.

\section{2 후막 코팅}

형광체 및 유리 혼합 페이스트 제조 시 사용된 황 색 형광체는 cerium이 도핑된 yttrium aluminum

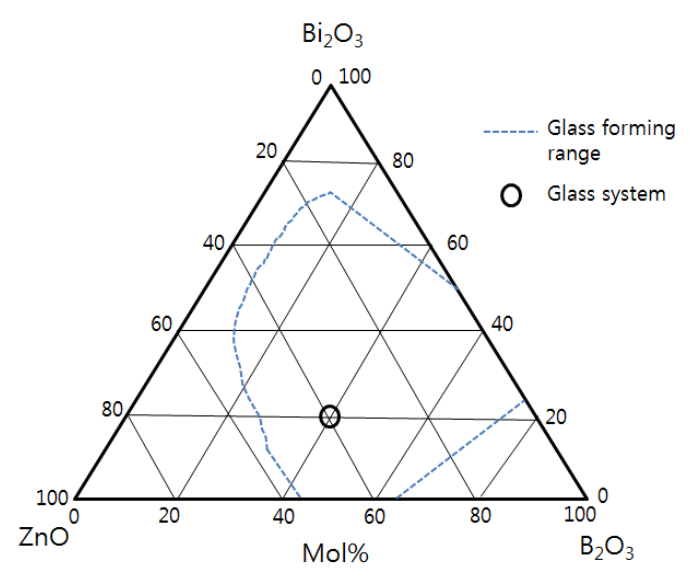

Fig. 1. Phase diagram of the $\mathrm{Bi}_{2} \mathrm{O}_{3}-\mathrm{B}_{2} \mathrm{O}_{3}-\mathrm{ZnO}$ system.

Table 1. The composition of paste.

\begin{tabular}{cccc}
\hline \multirow{2}{*}{$\begin{array}{c}\text { Sample } \\
\text { No. }\end{array}$} & \multicolumn{3}{c}{ Compositions (wt.\%) } \\
\cline { 2 - 3 } & Phosphor & Glass frit & Vehicle(\%) \\
\hline P8G2 & 80 & 20 & \multirow{2}{*}{30} \\
\hline P6G4 & 60 & 40 & \\
\hline P4G6 & 40 & 60 & \\
\hline P2G8 & 20 & 80 & \\
\hline
\end{tabular}

oxide YAG $\left(\mathrm{Y}_{3} \mathrm{Al}_{5} \mathrm{O}_{12} ; \mathrm{Ce}\right)$ 를 사용하였다. 글라스 프릿 과 형광체를 무게 비 기준으로 표 1과 같이 $20 \mathrm{wt} \%$ $\sim 80 \mathrm{wt} \%$ 로 변화시키면서 균일하게 혼합한 후, 페이 스트 제조를 위한 바인더를 전체 무게 비에 대하여 $30 \mathrm{wt} \%$ 첨가하여 형광체 페이스트를 제조하였다. 제 조한 페이스트를 $0.5 \mathrm{~mm}$ 두께를 갖는 boro-alumino silicate계 유리 기판 위에 스크린 프린팅법으로 인쇄 한 후 $80^{\circ} \mathrm{C}$ 에서 30 분간 건조하였다. 건조한 시편은 $600^{\circ} \mathrm{C}, 700^{\circ} \mathrm{C}, 800^{\circ} \mathrm{C}$ 에서 각각 2 시간 동안 열처리를 진행하였다.

\section{3 특성 평가}

제조한 글라스 프릿은 TMA (Q400, TA, USA)를 이용하여 전이점 $(\mathrm{Tg})$ 및 연화점 $(\mathrm{Ts})$ 을 측정하였다. 또한, 시편의 열처리 온도를 선정하기 위해 고온현미 경 (HKL-04-WASV, HKLAB Co., Korea)을 이용하 여 온도에 따라 연화되는 사진을 측정하였다. 열처리 가 끝난 색변환 렌즈의 미세구조 및 성분을 분석하기 
위해 SEM (scanning electron microscope, JSM-6380, JEOL)과 field emission scanning electron microscope (FE-SEM, JSM 6700, JEOL)을 이용하여 관찰하였다. 또한 색변환 렌즈 표면의 결정상을 알아 보기 위하여 X-ray diffractometer (D/max-2500/PC, Rigaku corporation)를 이용하여 분석하였다. X-ray 회절 분석에는 $40 \mathrm{kV}, 30 \mathrm{~mA}$ 에서 $\mathrm{Cu}-\mathrm{Ka}$ tube를 사 용하여 $2 \theta=10^{\circ} \sim 80^{\circ}$ 구간에서 측정하였다. 제조한 색변환 렌즈의 광 특성을 평가하기 위해 LED 패키지 는 $3 \mathrm{~W}$ 급의 remote-phosphor를 사용하여 측정하였 다. 점등 조건은 비교 표준이 되는 청색 $\mathrm{LED}$ 칩을 사용하여 점등하였고, 전류는 $0.25 \mathrm{~A}$, 전압은 $11.9 \mathrm{~V}$, 전력은 $2.98 \mathrm{~W}$ 로 전기적 특성은 모두 동일 조건으로 측정하였다. Remote-phosphor가 적용된 LED 패키지 의 광속, 광 효율, 평균 연색성지수 (CRI), 상관색 온도 (CCT)는 IES LM-79-08 (electrical and photometric measurements of solid-state lighting products)에 의 한 방법으로 측정을 실시하였다. 직류 전원 장치로 정 격전류를 공급하여 전기적 특성 및 광학적 특성의 편 차가 $0.5 \%$ 이하로 안정화되었을 때 측정하였다. 광 효 율은 Goniophotometer (C-type, PSI사)와 Power analyzer를 사용하였으며 연색지수 및 색 온도는 Integrating Sphere $(0.5 \mathrm{~m}$, PSI사)를 이용하였다.

\section{3. 결과 및 고찰}

Remote-phosphor LED용 색 변환 렌즈에 적용 되는 글라스 프릿의 열처리 온도를 확인하기 위해 측정한 TMA 결과를 그림 2에 나타내었다. 그림에 서 살펴보면 유리의 경우, 기울기가 변하는 온도에 서의 전이점과 그래프가 다시 상승하다가 꺾이는 부근에서 연화점을 나타내는데, 본 연구에서 사용한 $\mathrm{Bi}_{2} \mathrm{O}_{3}-\mathrm{B}_{2} \mathrm{O}_{3}-\mathrm{ZnO}$ 계 유리는 전이온도는 $380^{\circ} \mathrm{C}$, 연화 온도가 $450^{\circ} \mathrm{C}$ 를 나타내고 있다. 실제로 글라스 프 릿이 remote-phosphor의 제조 공정에서 적용되는 연화 상태를 확인하기 위해 고온 현미경을 이용하 여 관찰한 사진을 그림 3 에 나타내었다. 연화점 부 근은 $500^{\circ} \mathrm{C}$ 부터 바깥 부분의 수축이 시작되는 것 을 볼 수 있었고, $700{ }^{\circ} \mathrm{C}$ 이상의 온도에서는 글라스 가 완전히 녹아내려 유동성이 증가하는 현상을 확 인하였다. 따라서 제조 공정의 열처리 온도는 60 $0^{\circ} \mathrm{C}$ 부터 $700^{\circ} \mathrm{C}, 800^{\circ} \mathrm{C}$ 에서 각각 열처리를 진행하였 다.

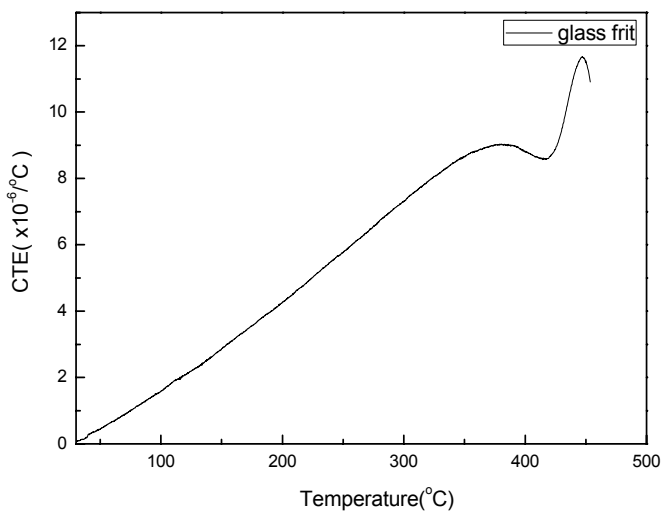

Fig. 2. TMA of $\mathrm{Bi}_{2} \mathrm{O}_{3}-\mathrm{B}_{2} \mathrm{O}_{3}-\mathrm{ZnO}$ system.

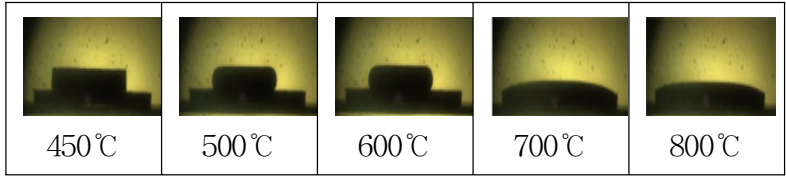

Fig. 3. Softening point images in $\mathrm{Bi}_{2} \mathrm{O}_{3}-\mathrm{B}_{2} \mathrm{O}_{3}-\mathrm{ZnO}$ systems.

그림 4는 제조 온도와 함량에 따라 제조된 색변환 optics 표면의 미세구조를 나타내었다. 형광체 함량에 따라 표면의 큰 차이를 확인할 수 있었다. 형광체 함 량이 글라스 프릿 함량보다 많은 P8G2 및 P6G4의 표면에서는 형광체 입자인 둥근 입자와 입자 사이에 글라스가 녹아 네크를 형성하고 있는 것을 확인할 수 있었다. 반면, 글라스 프릿 함량이 많은 색변환 렌즈 의 표면에서는 형광체 입자가 표면에 두드러지지 않 은 것을 볼 수 있다. P4G6 색변환 렌즈는 형광체 입 자 위로 글라스가 용융되어 표면을 덮고 있는 것을 볼 수 있고, 글라스 프릿 함량이 $80 \mathrm{wt} \%$ 인 P2G8 색 변환 렌즈 표면은 형광체 입자는 표면에 드러나지 않 고 대부분이 글라스가 평평한 상태로 표면에 나타난 것을 확인할 수 있었다. 특히, $800^{\circ} \mathrm{C}$ 에서 제조된 P2G8 표면에서는 유리로 덮힌 표면에 결정으로 보이 는 미세구조를 관찰할 수 있었다.

그림 5에서는 형광체와 글라스 프릿의 함량과 열처 리 온도에 따라 제조된 색변환 렌즈의 XRD 분석 결 과를 나타내었다. 형광체 함량에 따라, 열처리 온도에 따라 형광체와 글라스 프릿이 반응하여 어떠한 결정 


\begin{tabular}{|c|c|c|c|c|}
\hline $\begin{array}{l}\text { Treat. } \\
\text { ('C) }\end{array}$ & P8G2 & P6G4 & P4G6 & P2G8 \\
\hline 600 & & & & \\
\hline 700 & & & & \\
\hline 800 & & & & \\
\hline
\end{tabular}

Fig. 4. SEM images of the heat treatment lens surface. $\left(600^{\circ} \mathrm{C}, 700^{\circ} \mathrm{C}\right.$, and $\left.800^{\circ} \mathrm{C}\right)$.
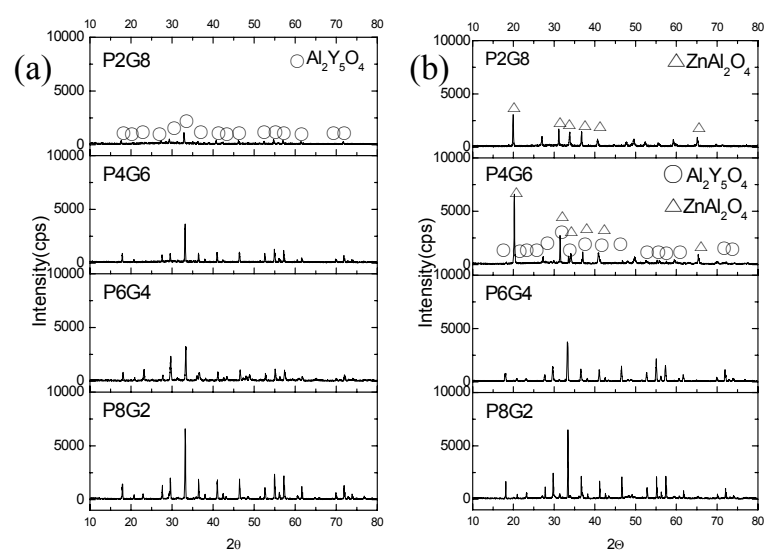

Fig. 5. XRD pattern of the heat treatment lens with various temperature. (a) $600^{\circ} \mathrm{C}$, (b) $800^{\circ} \mathrm{C}$.

상을 나타내는지 확인하였다. 분석 결과, 열처리 온도 가 $600^{\circ} \mathrm{C}$ 인 (a)의 결정상을 보면 모든 색변환 렌즈에 서 형광체의 주 피크인 $\mathrm{Al}_{2} \mathrm{Y}_{5} \mathrm{O}_{4}$ 피크가 존재하였고, 형광체 함량이 감소함에 따라 형광체의 주 피크의 세 기가 감소하고 $\mathrm{Bi}_{2} \mathrm{O}_{3}-\mathrm{B}_{2} \mathrm{O}_{3}-\mathrm{ZnO}$ 계 유리 프릿에 의한 비정질 피크가 나타나는 것을 볼 수 있었다. 이에 반 에, $800^{\circ} \mathrm{C}$ 에서 제조된 색변환 렌즈의 결정상에서는 $\mathrm{P} 8 \mathrm{G} 2$ 와 P6G4의 색변환 렌즈의 주 피크가 나타났지 만, $\mathrm{P} 4 \mathrm{G} 6$ 표면에서 $\mathrm{Al}_{2} \mathrm{Y}_{5} \mathrm{O}_{4}$ 피크와 $\mathrm{ZnAl}_{2} \mathrm{O}_{4}$ 의 이차 상이 생성된 것을 확인할 수 있었다. 그리고 P2G8 표 면에서는 형광체의 주 피크는 나타나지 않고 비정질 과 이차상이 존재하는 것을 확인할 수 있었다. 이는 $800^{\circ} \mathrm{C}$ 이상 온도에서 열처리 시 글라스 프릿과 형광

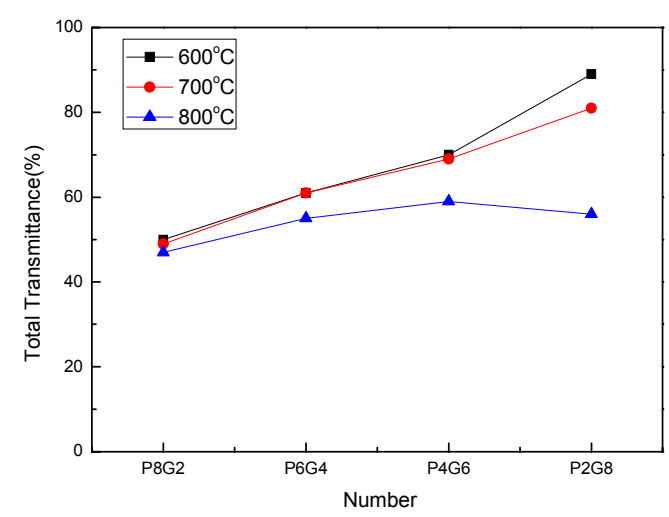

Fig. 6. Transmittance of the heat treatment lens with various temperature. $\left(600^{\circ} \mathrm{C}, 700^{\circ} \mathrm{C}\right.$ and $\left.800^{\circ} \mathrm{C}\right)$.

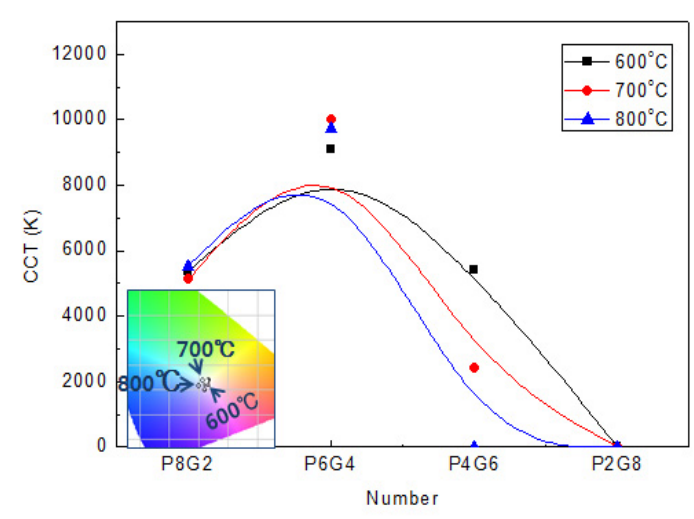

Fig. 7. CCT of the heat treatment lens with various temperature. $\left(600^{\circ} \mathrm{C}, 700^{\circ} \mathrm{C}\right.$ and $\left.800^{\circ} \mathrm{C}\right)$.

체가 반응하고 이로 인한 이차상이 생성된 것으로 보 여진다. 광원으로부터 발생하는 빛이 렌즈에서 색변 환 시, 빛의 확산광 및 산란되는 정도를 확인하기 위 해 적분구투과율을 측정하여 그림 6 에 나타내었다. 적분구투과율은 $600{ }^{\circ} \mathrm{C}$ 와 $700{ }^{\circ} \mathrm{C}$ 에서 제조한 색변환 렌 즈에서는 글라스 프릿의 함량이 증가함에 따라 50\% 에서 $80 \%$ 내외까지 증가하는 경향을 나타내었다. 반 면, $800^{\circ} \mathrm{C}$ 에서 제조한 경우, $\mathrm{P} 6 \mathrm{G} 4$ 색변환 렌즈까지는 글라스 프릿의 함량이 증가할수록 적분구 투과율이 $48 \%$ 에서 $58 \%$ 까지 증가하다가 P4G6 색변환 렌즈에 서 다시 $50 \%$ 까지 감소하는 것을 나타내었다. 이는 앞 선 $\mathrm{XRD}$ 측정 결과, 글라스 프릿이 재결정으로 인해 생성된 이차 상에 의해 적분구투과율이 감소한 것으 로 생각되어 진다. 이를 통해 청색 광원이 색변환 렌즈에 


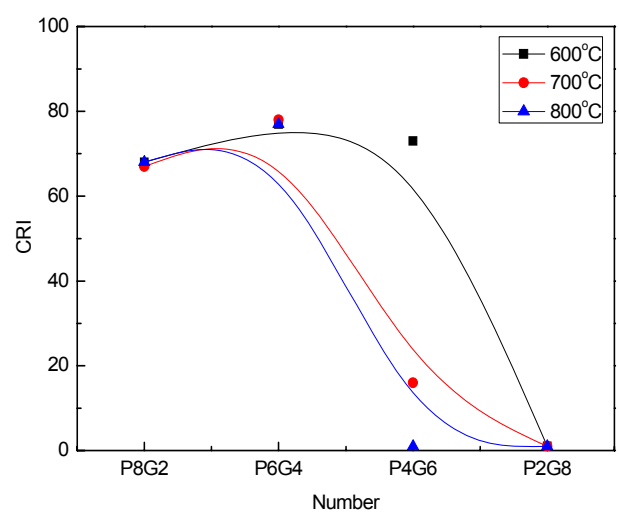

Fig. 8. CRI of the heat treatment lens with various temperature. $\left(600^{\circ} \mathrm{C}, 700^{\circ} \mathrm{C}\right.$ and $\left.800^{\circ} \mathrm{C}\right)$.

통과할 때, 재결정되지 않는 글라스 함량이 많을수록 빛이 확산 및 투과가 높은 것을 확인할 수 있었다. 또한, 열처리 온도가 증가할수록 투과율이 감소하는 것을 확인할 수 있었다.

그림 7에서는 열처리 조건에 따른 색 온도를 나타 내었는데, 형광체 함량이 $80 \mathrm{wt} . \%$ 인 P8G2 색 변환 렌즈의 경우 색 온도 값이 $5,500 \mathrm{~K}$ 정도를 나타나는 것을 확인할 수 있었다. 이 값은 백색 $\mathrm{LED}$ 의 조명으 로 적용을 위한 5,500 6,500 K 값의 범위에 있는 것 을 확인할 수 있었다 [8-10]. 그러나, 유리의 함량이 많아지는 P6G4 색변환 렌즈에서는 청색 영역으로 색 온도 값이 이동하고, 유리의 함량이 더 많은 조성인 $\mathrm{P} 4 \mathrm{G} 6$ 색변환 렌즈에서는 다시 황색 영역으로 감소하 다가 P2G8 색변환 렌즈에서는 측정치를 나타내지 못 하는 것을 볼 수 있다. 이러한 측정 결과는 색변환 렌즈의 표면 미세구조에서 $\mathrm{P} 8 \mathrm{G} 2$ 는 적은 유리 함량으 로 표면에 형광체 입자가 그대로 드러나 있어 많은 형광체로 인해 낮은 색 온도 값을 나타내고 있는 것 이라고 예상된다. 그러나 유리 함량이 많아지는 P6G4 조성에서는 형광체 함량이 P8G2보다 적어 청색 부 근의 높은 색 온도 값을 나타낸 것으로 예상된다. 또 한, 유리의 함량이 더욱 많아지는 P4G6 조성부터는 제조한 렌즈 표면을 유리가 덮을 뿐만 아니라, 형광 체와 유리 기판 사이의 유리 층으로 인해 칩으로부터 나오는 빛을 차단하게 되어 낮은 색 온도를 나타내는 것으로 보여진다.

그림 8은 각각의 열처리 온도에서 제조한 렌즈의 연 색지수를 나타내었다. 열처리 온도에 상관없이 P6G4

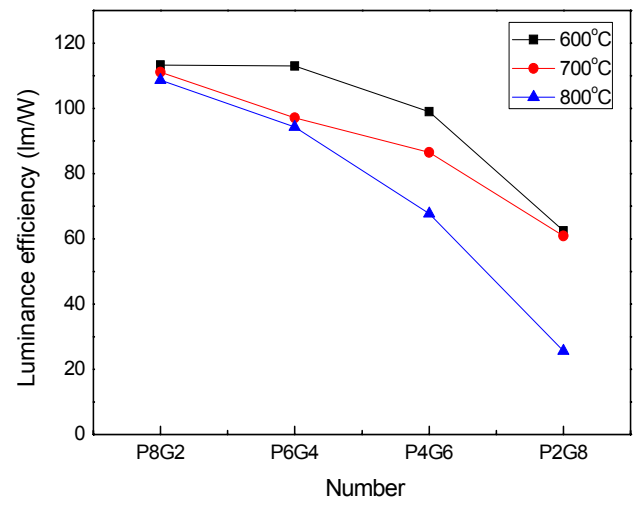

Fig. 9. Optic properties of the heat treatment lens with various temperature. $\left(600^{\circ} \mathrm{C}, 700^{\circ} \mathrm{C}\right.$ and $\left.800^{\circ} \mathrm{C}\right)$.

조성까지는 68 이상의 값을 나타내었으나, 유리 함량 이 많아짐에 따라 P6G4부터 글라스 프릿 함량이 증 가함에 따라 감소하는 경향을 나타내고 있고, 열처리 온도가 $700^{\circ} \mathrm{C}, 800^{\circ} \mathrm{C}$ 로 높아질수록 연색지수 값이 낮 아지고 있다. 이는 색 온도와 같은 결과로 유리 함량 이 많아지는 P4G6부터는 낮은 연화 온도를 갖는 유 리로 인해 유리 기판과 형광체 사이에 유리 층이 존 재하게 되어 칩으로부터 발광되는 빛이 차단되어 낮 은 연색지수 값을 나타내는 것으로 보여진다. 본 그 래프에서는 색 온도와 연색지수 측정 결과, P8G2 값 이 백색광에 가까운 값을 나타내고 있다.

그림 9 는 각 온도에서 제조된 색변환 렌즈의 광 효 율을 나타낸 결과이다. 형광체 함량이 증가함에 따라 광 효율은 증가하는 경향을 나타내고, 글라스 프릿 함량이 증가함에 따라 광 효율이 감소하는 경향을 나 타내고 있다. 또한, 열처리 온도가 높아질수록 같은 함량에서 광 효율이 감소하는 현상을 나타나고 있는 것을 확인할 수 있었다. 이는 결정상 분석에서 나타 난 결과에서 보여진 것처럼 $\mathrm{P} 4 \mathrm{G} 6$ 및 $\mathrm{P} 2 \mathrm{G} 8$ 의 경우 $800^{\circ} \mathrm{C}$ 에서 열처리한 색변환 렌즈에서 $\mathrm{Al}_{2} \mathrm{Y}_{5} \mathrm{O}_{4}$ 와 $\mathrm{ZnAl}_{2} \mathrm{O}_{4}$ 의 이차상의 생성으로 인해 광 효율에도 영향 을 미치는 것으로 볼 수 있다.

\section{4. 결 론}

Remote phosphor 렌즈 제조에 있어 형광체와 글라 스 프릿의 함량, 열처리 온도의 조건에 의해 광 특성 
이 미치는 영향에 대해 연구를 진행하였다. 형광체의 함량에 따른 렌즈는 글라스의 함량에 $40 \mathrm{wt} \%$ 인 $\mathrm{P} 6 \mathrm{G} 4$ 조성까지는 형광체 입자 사이에 글라스가 네크 를 형성하고 있는 미세구조를 가지고 있었다. 반면 글라스의 함량이 $60 \mathrm{wt} \%$ 인 P4G6 조성부터는 용융된 글라스가 형광체 표면을 평평하게 덮고 있는 미세구 조를 관찰할 수 있었다. 이러한 결과는 색 변환을 나 타내는 색 온도와 연색지수 수치에 영향을 미쳐 형광 체 입자 사이에 글라스를 네크를 형성하는 조성에서 높은 색 온도와 연색지수를 나타내는 것을 확인할 수 있었다. 또한, $600{ }^{\circ} \mathrm{C}$ 에서 렌즈를 열처리한 경우, 형광 체의 주성분인 $\mathrm{Al}_{2} \mathrm{Y}_{5} \mathrm{O}_{4}$ 결정상만이 나타났으나, 80 $0{ }^{\circ} \mathrm{C}$ 에서 열처리한 $\mathrm{P} 4 \mathrm{G} 6, \mathrm{P} 2 \mathrm{G} 8$ 에서는 형광체의 결정 외에 $\mathrm{ZnAl}_{2} \mathrm{O}_{4}$ 이차 상이 나타났다. 이러한 이차 상으 로 인해 제조한 렌즈는 광 특성 저하를 나타내는 것 을 확인할 수 있었다. 글라스의 함량이 $20 \mathrm{wt} \%$ 인 $\mathrm{P} 8 \mathrm{G} 2$ 조성을 이용하여 $600^{\circ} \mathrm{C}$ 에서 2시간 열처리한 경 우 조명으로 적합한 색 온도 $5,500 \mathrm{~K}$, 연색지수 68 , 광 효율 $118 \mathrm{~lm} / \mathrm{W}$ 를 갖는 것을 확인할 수 있었다.

\section{감사의 글}

본 연구는 2012년도 중소기업 산학연협력사업, 연 구 장비 활용기술개발사업인 'LM-80 열화시험기를 통한 내구수명이 보증된 저융점 유리 $\mathrm{LED}$ 패키지 개 발'로 지원받아 수행한 연구 과제입니다.

\section{REFERENCES}

[1] M. Lago and M. Meneghini, Microelectron. Reliab., 52, 2164 (2012).

[2] C. Sommer, P. Hartmann, P. Pachler, M. Schweighart, S. Tasch, G. Leising, and F. P. Wenzl, Opt. Mater., 31, 837 (2009).

[3] Z. Liu, S. Liu, K. Wang, and X. Luo, IEEE Photon. Technol. Lett., 20, 2027 (2008).

[4] Y. J. Kim, S. J. Hwang, and H. S. Kim, Materials Science Forum., 501, 578 (2006).

[5] F. J. Cheng, D. Deng, and J. Wang, Central South University of Technology, 17, 257 (2010).

[6] O. Sanz, E. Haro-Poniatowski, J. Gonzalo, and J. F. Navarro, J. Non-Crystalline Solids, 352, 761 (2006).

[7] S. H Im, Y. H. Na, N. J. Kim, D. H. Kim, C. W Whang, and B. K Ryu, Thin Solid Films, 518, e46 (2010). 